\title{
Natural enemy composition rather than richness determines pest suppression
}

\author{
Sanaa N. Alhadidi · John N. Griffin • Mike S. Fowler
}

Received: 21 June 2017 / Accepted: 7 February 2018/Published online: 19 February 2018

(C) The Author(s) 2018. This article is an open access publication

\begin{abstract}
Natural enemy (NE) biodiversity is thought to play an important role in agricultural pest suppression. However, the relative importance of the number of NE species (species richness), versus the particular combinations of species (species composition), in determining aphid suppression and ultimately crop yields, remains poorly understood. We tested the effects of NE richness and composition on pea aphids Acyrthosiphon pisum (Harris) and broad bean plants Vicia faba (Linn.). We used the larvae of two predator species, the ladybird Adalia bipunctata (Linn.) and the green lacewing Chrysopa carnea (Stephens), and the parasitic wasp Aphidius ervi (Haliday) as enemies. NEs generally reduced aphid density but did not increase final plant biomass, despite a significant negative correlation between aphid density and plant
\end{abstract}

Handling Editor: Marta Montserrat

S. N. Alhadidi $(\bowtie) \cdot$ J. N. Griffin · M. S. Fowler

Department of Biosciences, College of Science, Swansea

University, Singleton Park, Swansea SA2 8PP, UK

e-mail: 748133@swansea.ac.uk;

sanaa.abed@sciences.uodiyala.edu.iq

J. N. Griffin

e-mail: j.n.griffin@swansea.ac.uk

M. S. Fowler

e-mail: m.s.fowler@swansea.ac.uk

S. N. Alhadidi

Department of Biosciences, College of Science,

University of Diyala, Baqubah, Iraq biomass. Among NE treatments, species richness had an inconsistent effect on aphid density. The composition of NEs within richness levels also affected final aphid density: the ladybird was a key species among the treatments in controlling aphid density and was especially effective in combination with the parasitoid. This ladybird/parasitoid combination also appeared to drive the higher level of suppression observed at the two, relative to three, species richness levels. Although these three species of aphid NEs are commonly used in aphid control, this is the first study, to our knowledge, that simultaneously examined these three species and highlighted the composition effect between the A. bipunctata and A. ervi. In conclusion, increasing NE species richness had an inconsistent effect on aphid density. Meanwhile, the presence of a key species (the ladybird) and its combination with a parasitoid was an important determinant of aphid biological control.

Keywords Biodiversity $\cdot$ Species richness $\cdot$ Species composition · Key species · Aphid control · Natural enemies

\section{Introduction}

Natural enemies (NEs; i.e., predators, parasitoids and pathogens) aid in the regulation of harmful pests, allow the reduction or elimination of pesticides, and 
therefore play an important role in agricultural ecosystems (Cardinale et al. 2012; Crowder et al. 2010). However, the role of biodiversity among natural enemies in determining the efficacy of pest suppression is controversial (Denoth et al. 2002; Finke and Denno 2004; Letourneau et al. 2009). In particular, the relative roles of species richness and species composition in determining pest control, and how these cascade across trophic levels to influence crop growth, remain unclear (Casula et al. 2006).

$\mathrm{NE}$ richness can have positive or negative effects on prey suppression, depending on the prevailing mechanism of interaction between enemies. NE richness may help to control the pest if NEs show complementarity, i.e., differ in their resource use (e.g., in space, time, feeding mechanism; Gontijo et al. 2015; Symondson et al. 2002), which may reduce the strength of competition between NEs (Northfield et al. 2010) and/or preclude prey escape (Losey and Denno 1998). Alternatively, NE richness may reduce the strength of pest control if intraguild predation (IGP) among the diverse enemies is present (VanceChalcraft et al. 2007), or if they show interference through direct competition (Schoener 1983). While positive effects of NE richness on prey suppression are more common than negative effects (Griffin et al. 2013), the range of interactions between NE species may explain variation in the direction of the relationship between natural enemy biodiversity and pest control in observational (Letourneau et al. 2009) and experimental (Griffin et al. 2013) studies.

Species composition can also be an important determinant of prey suppression. There is considerable evidence that NE composition or identity drives pest control even within diverse guilds of NEs (e.g., Chalcraft and Resetarits 2003; Long and Finke 2014). Species composition may be important if particular combinations or sets of species have traits that lead to strong complementarity (e.g., day versus night foragers; Petersen and Woltz 2015), positive interactions (e.g., leaf versus ground foraging species; Losey and Denno 1998) or negative interactions (e.g., large versus small species; Griffen and Byers 2006). Species composition effects can also depend on the inclusion of particular species that show more efficiency than others. In the biological control of aphids, the focus of our study, species of the ladybird family (Coccinellidae) have previously been identified as key species (Long and Finke 2014; Straub and Snyder 2006a).

Both richness and composition of NEs may be important indirect determinants of plant biomass but their effects on plant biomass have received little attention (Griffin et al. 2013). Although previous experiments have illuminated the multiple interactions among NEs, and identified species composition as an additional control of prey suppression, most of these experiments have focused exclusively on two trophic levels (NE and herbivore; e.g., Gontijo et al. 2015; Losey and Denno 1998; Snyder et al. 2004). Nevertheless, a few experiments illustrate the potential for variable outcomes in the cascading effects of increasing NE richness. For example, NE richness has been shown to increase alfalfa and collard crop biomass (Cardinale et al. 2003; Snyder et al. 2006), while other studies demonstrate the potential for increased NE richness to reduce plant biomass in salt marshes (Finke and Denno 2004, 2005). Here, we address the shortage of studies investigating the relative roles of $\mathrm{NE}$ richness and composition in regulating pests and plant biomass in an experimental model system using aphids.

Aphids are economically significant pests globally, as many aphid species are pests in agriculture, horticulture and forestry (Blackman and Eastop 2008), and act as a significant vector for plant viruses (Brault et al. 2010). These pests can invade and establish rapidly in an area: they spread quickly at local scales through the winged form and disperse more widely via transportation of host plants by humans (Messing et al. 2007). Reproducing both sexually and parthenogenetically (Harrewijn and Minks 1989), with high growth and development rates, aphids can start reproduction 7-10 days after birth (Dixon 1998). Aphids are attacked by different taxa including: aphid parasitoids with high hostspecificity (Hymenoptera, mainly Braconidae and Aphelinidae; Boivin et al. 2012), generalist aphidophagous predators (e.g., Coccinellidae and Syrphidae larvae), generalist predators that frequently attack aphids as well as other prey species (e.g., ground beetles and spiders) (Symondson et al. 2002) and entomophagous fungi that cause diseases to aphids (e.g., Erynia neoaphidis and Entomophthora planchoniana; Milner 1997). The importance of aphids as agricultural pests, their rapid population growth rates, and their diverse suite of NEs all render aphids a 
suitable model for investigating the roles of natural enemies' biodiversity in pest control and other fundamental questions in ecology and evolution (Huang and Qiao 2014).

In this study, we aimed to investigate the relative importance of the number (species richness) and the species composition of NE species in determining pest control and ultimately crop yield. Our model system consisted of pea aphid, Acyrthosiphon pisum (Homoptera: Aphididae), colonies that were exposed to different combinations of three NE species on broad bean plants Vicia faba under greenhouse conditions. The NE species we used were the ladybird Adalia bipunctata (Coleoptera: Coccinellidae), the green lacewing Chrysopa carnea (Neuroptera: Chrysopidae), and a specialist parasitoid Aphidius ervi (Hymenoptera: Braconidae). We chose these NE species because they exhibit a diversity of ecological traits and thus have the potential to exhibit species identity, composition and diversity effects which may be important to consider in managing NEs in agricultural settings. Further, they are widely commercially available, so can easily be used in combination in greenhouses. Despite the fact that these species of aphid natural enemies have frequently been used in aphid control, this is the first study, to our knowledge, that combined these three species together.

We hypothesised that, in our study system, the presence of NEs suppresses prey density (H1a) and increases plant biomass (H1b). We further hypothesised that the effect of NEs on these response variables depends on the richness and composition of NEs. Specifically, we hypothesised that species richness increase pest suppression (H2a) and plant biomass (H2b), and species composition (within species richness levels one and two) increase pest suppression (H3a) and plant biomass (H3b). Finally, we hypothesised the presence of a single key species-the ladybird-determines prey suppression (H4a) and plant biomass (H4b).

\section{Materials and methods}

\section{Greenhouse experiment}

This study was conducted in a glass greenhouse at Swansea University between 6/6/2015 and 30/7/2015.
Initial plant growth and creation of mesocosms

Starting on 6/6/2015 we grew broad bean plants (the Sutton, from Victoriana Nursery Gardens, Kent, UK) in 40 pots (dimensions: diameter $22 \mathrm{~cm}$, depth $25.4 \mathrm{~cm}$ ), filled with compost. The pots were covered with tomato cages (Conical Plant Support Ring $32 \mathrm{~cm}$ dia. $\times 75 \mathrm{~cm}$ by Gardman from Crowders, Lincoln, UK) and fine mesh (Extra-Fine Insect Netting $1.8 \mathrm{~m}$ from Wondermesh, Laurencekirk, UK) immediately after sowing. We tied the mesh around the pot with rubber bands to avoid non-experimental insects entering, or experimentally introduced insects leaving the cages (see Experimental design below). We also hung sticky insect traps in each cage during the plant establishment phase to capture any invading insects. These traps were removed when introducing the aphids. Plants were watered liberally every four days during the initial growth phase and throughout the experiment.

\section{Sourcing and culturing of animals}

We established a colony of pea aphids Acyrthosiphon pisum in bugdorm cages [BugDorm-4 Insect Rearing Cage $(47.5 \times 47.5 \times 47.5 \mathrm{~cm})]$ in a constant temperature room at $20 \pm 2{ }^{\circ} \mathrm{C}$, RH $47 \pm 8 \%$ and light regime L:D 16:8 on broad bean plants three months before starting the experiment. Natural enemies were supplied by Fargro (Arundel, UK). We used the larvae of two generalist predator species, the ladybird Adalia bipunctata, and the green lacewing Chrysopa carnea, and a specialist parasitoid Aphidius ervi.

\section{Experimental design}

The design consisted of a NE-free treatment, all three single-species NE treatments, all three possible twospecies NE combinations and the mixture of all three $\mathrm{NE}$ species [because of the restricted range of NE species available for our experiment (Cardinale et al. 2003)]. There was thus a gradient of NE richness (onethree species) and variation in composition within the one and two-species richness levels, allowing both sources of variation to be investigated. We used a substitutive approach, maintaining a constant total number of natural enemy individuals (six) across treatments with different diversities, i.e., six individuals of a single enemy species, three individuals each 
of two enemy species, or two individuals each of all three enemy species. A similar design has previously been used to test the effects of species richness and composition on ecosystem processes (Finke and Snyder 2008; O'Connor and Bruno 2009). The additive design detects the interspecific interactions, while the substitutive design highlights the interspecific interaction relative to the intra-specific interaction, which is the main interest of our study. The strengths and weaknesses of both experimental approaches (substitutive and additive) have been debated at length in many studies (Griffen and Byers 2006; Straub and Snyder 2006b). Five replicates of each treatment were randomly assigned to mesocosms.

\section{Establishing the experiment and experimental conditions}

We added ten aphids to each caged plant on 2/7/2015. After two weeks, we introduced first and second larval stages of both the ladybird A. bipunctata and the green lacewing $C$. carnea, and after a further day we introduced the parasitic wasps. The delayed introduction of A. ervi was to allow the female parasitic wasp to lay its egg in the least risky place away from predators (Frago and Godfray 2014; Nakashima et al. 2006). During the experiment, the maximum and minimum greenhouse daily temperatures were $(44.5 \pm S D$ 7.4, $12.8 \pm \mathrm{SD} 2.9)$ and humidity (93.3\% \pm SD 6.1, $18.3 \% \pm$ SD 13.3), respectively, with natural light.

\section{Data collection}

The experiment finished 15 days after introducing the parasitoid which is enough time for the parasitized aphid to mummify (Malina and Praslička 2008). Aphids were collected on the final day and frozen for later counting but the final enemy densities were not recorded. Though flowers of broad bean plant are hermaphroditic, and both self- and cross-pollination are possible, the typical crop is formed when plants are visited by pollinators (Drayner 1959), an interaction which was not possible in our caged plants. We used plant biomass as indicator of plant yield, which in studies of pollinated broad bean plants has been shown to correlate strongly with crop yield (Daur et al. 2011). Plant shoots were dried in an oven at $60{ }^{\circ} \mathrm{C}$, and checked daily until reaching constant mass, then weighed.

\section{Data analysis}

Two replicates of the lacewing/parasitoid treatments were removed before analysis due to plant death before the end of the experiment. We chose a single factor negative binomial generalized linear model with a log link function (GLM, using the MASS package, Venables and Ripley 2002) as a model for testing the final aphid number as a function of NE treatment, followed by a series of planned contrasts designed to test our hypotheses. We used planned contrasts instead of other biodiversity metrics, e.g., those outlined in Petchey (2003). Planned contrasted obtained the mean square error from the full model (negative binomial GLM), thus use an estimate of error derived from within-group variability across all treatments in the study. Therefore, this approach is a more powerful statistical test for an effect of diversity or ecosystem function than just considering the mean values in the measures summarised by Petchey (2003). The negative binomial GLM outperformed a Poisson GLM, based on AIC comparison, therefore we only present those results. We implemented the multiple comparisons using the multcomp package (Hothorn et al. 2008), a procedure which deals with variation among multiple means under heteroscedasticity in unbalanced designs (Herberich et al. 2010). To test H1a, we applied a planned linear contrast between the control treatment (NE-free) and all NE treatments combined (NEs-present). To assess the effect of NE species richness on final aphid number (H2a), we contrasted all possible species richness levels (i.e., one versus two, one versus three, two versus three). The planned contrasts test of H2aII also accounts for a sampling effect by comparing the average performance of each individual species with polyculture performance. To investigate the effect of NE composition on prey density (H3a), we contrasted treatments of varying composition within richness levels [i.e., single species: Ladybird (Lad) versus Lacewing (Lac), Lad versus Parasitoid (Par), Lac versus Par; two-species combinations: $\mathrm{Lad}+\mathrm{Lac}$ versus $\mathrm{Lad}+\mathrm{Par}, \mathrm{Lad}+\mathrm{Lac}$ versus $\mathrm{Lac}+\mathrm{Par}$, $\mathrm{Lac}+$ Par versus Lad + Par]. To test whether the ladybird is a key NE species (H4a), we contrasted treatments that included the ladybird (Lad, Lad + Lac, Lad + Par, All) versus those NE-present treatments 
that did not (Lac, Par, Lad + Par). To test the hypothesis that NEs generally increase plant biomass we used one-way ANOVA testing final plant biomass as a function of NE treatment. As there was no significant difference among NE treatments with respect to plant biomass (H1b) we did not run any further analysis to test other hypotheses relating to this response (H2b, H3b, H4b). We additionally used Spearman's rank correlation to explore the relationship between aphid density and plant biomass. All data analysis and figures were performed with the statistical program $\mathrm{R}$ version 3.3.3 (R Core Team 2017).

\section{Results}

The natural enemy treatments affected final aphid number $\left(\chi^{2}=35.93, d f=7, \quad P<0.001\right)$. Planned contrasts revealed that natural enemies (NEs) generally reduced aphid number across species richness and composition treatments (H1a, $Z=6.49, P<0.001$, Table 1; Fig. 1), but did not affect plant biomass (H1b, $F_{7,30}=2.30, P=0.053$, Fig. 2). Aphid suppression was not affected by increasing NE richness from two to three species (H2, Table 1).
NE composition within richness level affected final aphid density (H3a, Table 1; Fig. 1). The two-species combination of ladybird and parasitoid suppressed aphids to a lower density than the ladybird and lacewing (H3aIV) or the lacewing and parasitoid (H3aVI). Indeed, the ladybird and parasitoid led to the lowest aphid density of all NE treatments (Fig. 1). There were no differences between single-species composition treatments (H3aI-III). The planned contrast between treatments including versus excluding the ladybird showed ladybird presence significantly improved aphid suppression (H4a, Table 1). Species composition did not affect plant biomass (Fig. 2). Nevertheless, the relationship between aphid density and plant biomass across all NE treatments was supported by the negative correlation between these variables $(r=-0.500, P=0.001$; Fig. 3 ).

\section{Discussion}

Our experimental system showed that aphid suppression was impacted by natural enemy species composition, especially the presence of the ladybird and its combination with the parasitoid. We also found

Table 1 Results of planned comparison linear hypothesis tests

\begin{tabular}{|c|c|c|c|c|c|}
\hline Hypothesis no. & Linear hypotheses (testing difference $=0$ ) & Estimate & SE & $\mathrm{Z}$ value & $P$ value \\
\hline H1a & NE-free-NE-present & 1.46 & 0.26 & 6.49 & $<0.001$ \\
\hline $\mathrm{H} 2 \mathrm{aI}$ & $\mathrm{R} 1-\mathrm{R} 2$ & 0.51 & 0.30 & 1.68 & 0.552 \\
\hline $\mathrm{H} 2 \mathrm{aII}$ & $\mathrm{R} 1-\mathrm{R} 3$ & -0.91 & 0.54 & -1.69 & 0.545 \\
\hline H2aIII & $\mathrm{R} 2-\mathrm{R} 3$ & -1.41 & 0.53 & -2.67 & 0.070 \\
\hline $\mathrm{H} 3 \mathrm{aI}$ & Lad-Lac & -1.06 & 0.59 & -1.81 & 0.435 \\
\hline H3aII & Lad-Par & -0.87 & 0.55 & -1.59 & 0.616 \\
\hline H3aIII & Lac-Par & 0.19 & 0.50 & 0.37 & 1.000 \\
\hline H3aIV & $\mathrm{Lad}+\mathrm{Lac}-\mathrm{Lad}+\mathrm{Par}$ & 4.46 & 0.50 & 8.93 & $<0.001$ \\
\hline $\mathrm{H} 3 \mathrm{aV}$ & $\mathrm{Lad}+\mathrm{Lac}-\mathrm{Lac}+\mathrm{Par}$ & -0.92 & 0.39 & -2.33 & 0.165 \\
\hline $\mathrm{H} 3 \mathrm{aVI}$ & $\mathrm{Lac}+\mathrm{Par}-\mathrm{Lad}+$ Par & -5.39 & 0.58 & -9.28 & $<0.001$ \\
\hline $\mathrm{H} 4 \mathrm{a}$ & Lad-present-Lad-free & -1.46 & 0.29 & -5.03 & $<0.001$ \\
\hline
\end{tabular}

Treatment labels are: natural enemies absent (NE-free), natural enemies present (NE-present), level one richness (R1), level two richness (R2), level three richness (R3), Adalia bipunctata (Lad), Chrysopa carnea (Lac), Aphidius ervi (Par), treatment included the ladybird (Lad-present), treatment excluded the ladybird (Lad-free). The following hypotheses were tested: (1) H1a: Effect of NEs on aphid density (NE-free versus NE-present). (2) H2a: Effect of NE richness (I: R1 versus R2; II: R1 versus R3; III: R2 versus R3). (3) H3a: Effect of NE composition within species richness levels: one species (Lad versus Lac, Lad versus Par, Lac versus Par), twospecies ( Lad + Lac versus Lad + Par, Lad + Lac versus Lac + Par, Lac + Par versus Lad + Par). (4) H4a: Effect of Ladybirds (Lad-present versus Lad-free). Estimates and SE for linear hypotheses represent differences between $\log _{10}$ [mean (number of aphids)] in contrasted treatments, e.g., H1a; $\log _{10}$ [mean (number of aphids in the NEs-free)]- $\log _{10}$ (mean (number of aphid in NEs-present)). The $z$ values are based on Wald tests 


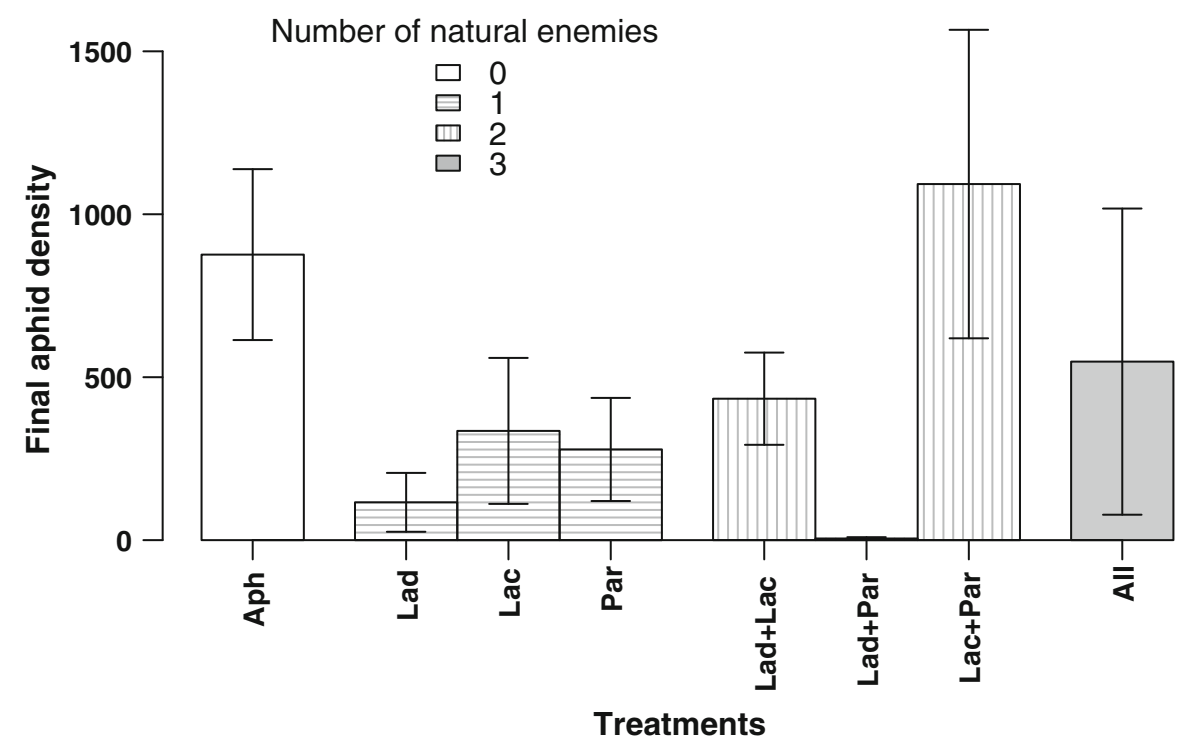

Fig. 1 Final aphid density response to experimental treatments. Treatments are labeled as aphid, Acyrthosiphon pisum alone (Aph), the aphid and natural enemies' treatments (Adalia bipunctata (Lad), Chrysopa carnea (Lac), Aphidius ervi (Par), A. bipunctata + C. carnea $(\mathrm{Lad}+\mathrm{Lac})$, A. bipunctata $+A$. ervi $(\mathrm{Lad}+\mathrm{Par})$, C. carnea + A. ervi $(\mathrm{Lac}+\mathrm{Par})$, the three NEs (All)). Error bars show $\pm 95 \% \mathrm{Cls}$, based on negative binomial generalized linear model. See Table 1 for results of planned comparisons

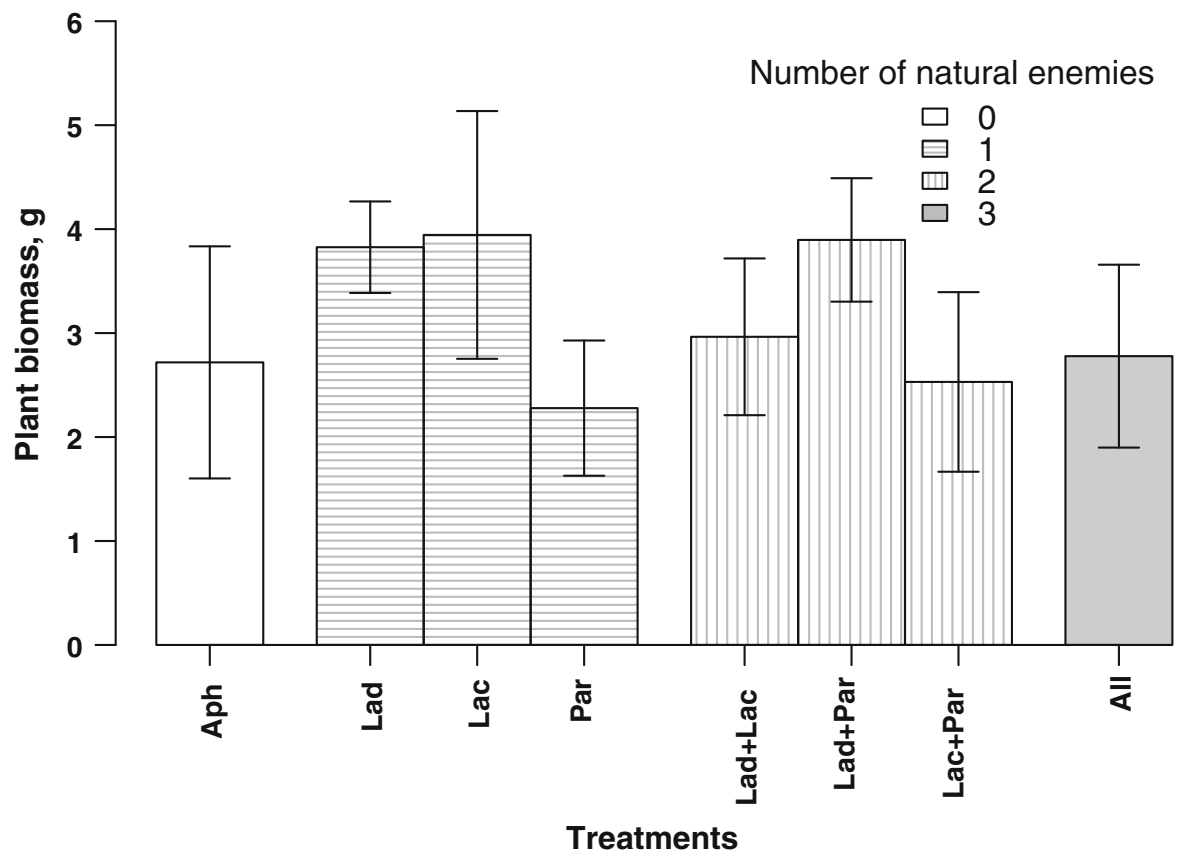

Fig. 2 Plant biomass response to experimental treatments. Treatments are labeled as aphid Acyrthosiphon pisum alone (Aph), the aphid and natural enemies' treatments (Adalia bipunctata (Lad), Chrysopa carnea (Lac), Aphidius ervi (Par),
A. bipunctata + C. carnea $(\mathrm{Lad}+\mathrm{Lac})$, A. bipunctata $+A$. ervi ( $\mathrm{Lad}+\mathrm{Par})$, C. carnea + A. ervi $(\mathrm{Lac}+\mathrm{Par})$, the three NEs (All)). Error bars show $\pm 95 \% \mathrm{Cls}$ based on 1-way ANOVA 


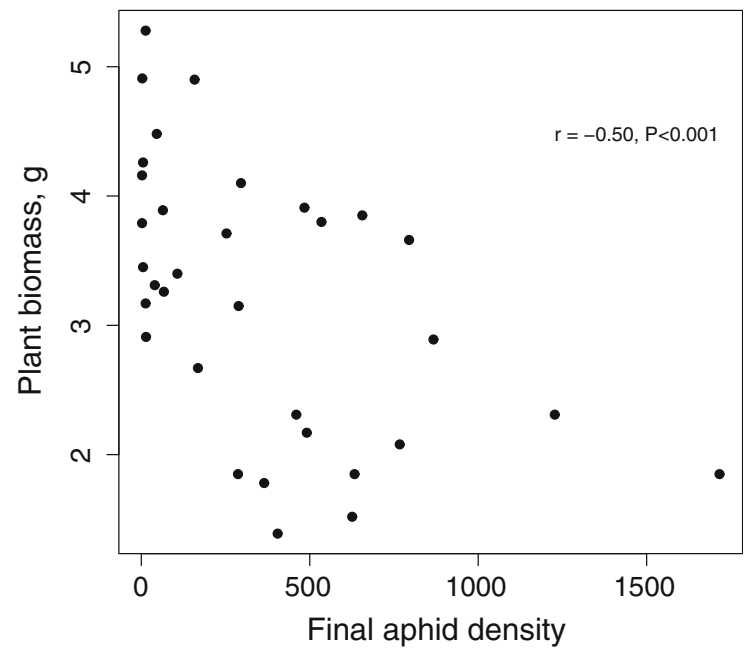

Fig. 3 Relationship between aboveground plant biomass (g) and final aphid density across natural enemies' treatments

evidence of a species richness effect. The combined two-species treatments showed greater aphid suppression than the three-species treatment. However, this potential richness effect was driven by the ladybird and parasitoid two-species combination, which was disrupted by the addition of the lacewing in the threespecies treatment.

The ladybird and parasitoid treatment had a dominant influence in our study (Table 1). This high control performance of the combination of A. bipunctata and $A$. ervi is for the first time demonstrated between these two species. One explanation for the efficiency of this combination is the contrasting foraging modes of the generalist predator (ladybird) and the parasitoid (Snyder et al. 2008). Previous studies have also reported enhanced aphid suppression under this combination of foraging modes (Gontijo et al. 2015; Snyder et al. 2004). Complementarity may be driven by female parasitoids spatially avoiding predation by selecting microhabitats for egg laying that have not been visited by generalist predators such as ladybirds (Nakashima and Senoo 2003). These groups of natural enemies may also show complementarity in the size and status of aphids attacked, which in theory would reduce competition between NEs (Casula et al. 2006). With respect to size, larval ladybirds have been shown to select smaller aphids (Khan and Khan 2002), whereas parasitoids may prefer larger, middle-aged, aphids (He and Wang 2006). With respect to status, two ladybird species have shown preference for non-parasitized over mummified aphids (Fu et al. 2017). We note, however, that the lacewing is also a generalist predator but showed no such evidence of complementarity with the parasitoid. This might be explained by observations in previous studies that lacewing prefer eating parasitized aphids (Hindayana et al. 2001; Rocca and Messelink 2017), which would lead to overlap rather than complementarity in their resource use. Future work should also examine these proposed mechanisms to elucidate why only particular predator-parasitoid combinations lead to efficient prey suppression.

In addition to the compositional effect driven by the ladybird and parasitoid, we also detected a generally positive effect of ladybird presence (Table 1). Combined, these results add to evidence indicating that $\mathrm{NE}$ composition and identity is an important determinant of ecosystem functions (Chalcraft and Resetarits 2003), including the control of aphids (e.g., Denoth et al. 2002; Long and Finke 2014; Straub and Snyder 2006a). Coccinellids have been highlighted as efficient aphid predators in both observational and experimental studies (Long and Finke 2014; Riddick 2017; Straub and Snyder 2006a). Why did ladybirds outperform the other natural enemies in our study? Despite exhibiting prey size preferences, ladybirds can consume individual aphids regardless of their size (Khan and Khan 2002), while the parasitoids require a particular host age and size for their eggs to develop (He and Wang 2006). In addition, parasitoids are limited in the number of eggs they can lay (Dieckhoff et al. 2014), whereas ladybird larvae consume continuously through their development. Ladybirds were also much more effective predators than the other generalist predator, lacewings, consistent with a previous study which suggests a related species of ladybird (Coccinella septempunctata) has both faster development and higher consumption rates of pea aphids than lacewing (Hindayana et al. 2001). Another explanation for the different effects of ladybirds and lacewings may lie in their feeding strategies and how they handle their pea aphid prey. Ladybirds tend to consume the pea aphids rather quickly, leading to reduced aphid alarm pheromone emitted. However, lacewings eat more slowly resulting in aphids emitting greater alarm pheromone (Joachim et al. 2013). Pea aphids tend to drop off a plant when they perceive the alarm pheromone (Harrison and Preisser 2016), which may limit the subsequent predation rates of lacewing. 
Our analysis indicated a negative effect of richness, between two and three species. This effect disappeared when the ladybird/parasitoid treatment was excluded from the analysis indicating that this treatment drove the greater prey suppression observed at the two versus three species level. The lacewing appears to have disrupted complementarity between the ladybird and parasitoid, probably through negative interactions (IGP, interference) with the other NEs (Noppe et al. 2012). Although less common than positive effects, a few previous studies have reported no effects of NE richness on prey suppression using a similar (substitutive) experimental design (Straub and Snyder 2006a; O'Connor and Bruno 2009). Our result shows that these effects can be non-linear (only between multispecies treatments) and mediated by the disruption of particularly effective species combinations (i.e., ladybird/parasitoid). We note that, while we did not find a consistent effect of NE richness on aphid suppression in our simplified experimental system, they should not be discounted in more complex systems or over larger spatio-temporal scales (Griffin et al. 2013).

The role of NEs in supressing herbivore effects on plants represents the core aim of both conservation of NE biodiversity and biological control (Straub et al. 2008). If NEs suppress pest density, plant biomass and associated products are expected to increase (Cardinale et al. 2003; Snyder et al. 2008). The hypothesised positive effect of NEs on plant biomass was not supported in our study. Again, this must be interpreted in light of the limited spatio-temporal scale (Snyder et al. 2008). Nevertheless, the negative correlation between aphid density and plant biomass (Fig. 3) indicates that reduction of aphid density by NEs is associated with increased plant biomass, a common finding in agricultural systems (e.g., Birkhofer et al. 2016).

In conclusion, this work confirms the role of NE species composition in controlling an important agriculture pest, the pea aphid, and reveals the potential for negative interactions between $\mathrm{NE}$ species to generate negative biodiversity effects. In using a small pool of species (three) and a small spatio-temporal scale, our study is typical of experimental NE biodiversity studies. Future studies should aim to extend the number of species - and species combinations-considered, as well as the spatio-temporal scale. Future studies should also more closely examine the mechanistic basis for multi-species composition effects, a goal that is likely to be aided by considering the traits of species.

Acknowledgements We thank Dirk Sanders (University of Exeter) for providing pea aphids. For funding this research we thank the Ministry of Higher Education and Scientific Research (Iraq), and an EU Marie Curie Career Integration Grant (FP7 MC CIG 61893) to JG.

Open Access This article is distributed under the terms of the Creative Commons Attribution 4.0 International License (http:// creativecommons.org/licenses/by/4.0/), which permits unrestricted use, distribution, and reproduction in any medium, provided you give appropriate credit to the original author(s) and the source, provide a link to the Creative Commons license, and indicate if changes were made.

\section{References}

Birkhofer K, Arvidsson F, Ehlers D, Mader VL, Bengtsson J, Smith HG (2016) Landscape complexity and organic farming independently affect the biological control of hemipteran pests and yields in spring barley. Landsc Ecol 31:567-579

Blackman RL, Eastop VF (2008) Aphids on the world's herbaceous plants and shrubs, vol 2. John Wiley, New York

Boivin G, Hance T, Brodeur J (2012) Aphid parasitoids in biological control. Can J Plant Sci 92:1-12

Brault V, Uzest M, Monsion B, Jacquot E, Blanc S (2010) Aphids as transport devices for plant viruses. C R Biol 333:524-538

Cardinale BJ, Harvey CT, Gross K, Ives AR (2003) Biodiversity and biocontrol: emergent impacts of a multi-enemy assemblage on pest suppression and crop yield in an agroecosystem. Ecol Lett 6:857-865

Cardinale BJ, Duffy JE, Gonzalez A, Hooper DU, Perrings C, Venail P, Narwani A, Mace GM, Tilman D, Wardle DA, Kinzig AP (2012) Biodiversity loss and its impact on humanity. Nature 486:59-67

Casula P, Wilby A, Thomas MB (2006) Understanding biodiversity effects on prey in multi-enemy systems. Ecol Lett 9:995-1004

Chalcraft DR, Resetarits WJ (2003) Predator identity and ecological impacts: functional redundancy or functional diversity? Ecology 84:2407-2418

Core Team R (2017) R: A language and environment for statistical computing. R Foundation for Statistical Computing, Vienna

Crowder DW, Northfield TD, Strand MR, Snyder WE (2010) Organic agriculture promotes evenness and natural pest control. Nature 466:109-112

Daur I, Sepetoğlu H, Sindel B (2011) Dynamics of faba bean growth and nutrient uptake and their correlation with grain yield. J Plant Nutr 34:1360-1371

Denoth M, Frid L, Myers JH (2002) Multiple agents in biological control: improving the odds? Biol Control 24:20-30 
Dieckhoff C, Theobald JC, Wäckers FL, Heimpel GE (2014) Egg load dynamics and the risk of egg and time limitation experienced by an aphid parasitoid in the field. Ecol Evol 4:1739-1750

Dixon A (1998) Aphid ecology: an optimisation approach. Chapman and Hall, London

Drayner JM (1959) Self-and cross-fertility in field beans (Vicia faba Linn.). J Agric Sci 53:387-403

Finke DL, Denno RF (2004) Predator diversity dampens trophic cascades. Nature 429:407-410

Finke DL, Denno RF (2005) Predator diversity and the functioning of ecosystems: the role of intraguild predation in dampening trophic cascades. Ecol Lett 8:1299-1306

Finke DL, Snyder WE (2008) Niche partitioning increases resource exploitation by diverse communities. Science 321:1488-1490

Frago E, Godfray HCJ (2014) Avoidance of intraguild predation leads to a long-term positive trait-mediated indirect effect in an insect community. Oecologia 174:943-952

Fu W, Yu X, Ahmed N, Zhang S, Liu T (2017) Intraguild predation on the aphid parasitoid Aphelinus asychis by the ladybird Harmonia axyridis. BioControl 62:61-70

Gontijo LM, Beers EH, Snyder WE (2015) Complementary suppression of aphids by predators and parasitoids. Biol Control 90:83-91

Griffen BD, Byers JE (2006) Intraguild predation reduces redundancy of predator species in multiple predator assemblage. J Anim Ecol 75:959-966

Griffin JN, Byrnes JE, Cardinale BJ (2013) Effects of predator richness on prey suppression: a meta-analysis. Ecology 94:2180-2187

Harrewijn P, Minks AK (1989) Aphids: their biology, natural enemies, and control. Elsevier, New York

Harrison KV, Preisser EL (2016) Dropping behavior in the pea aphid (Hemiptera: Aphididae): how does environmental context affect antipredator responses? J Insect Sci 16:89. https://doi.org/10.1093/jisesa/iew066

He XZ, Wang Q (2006) Host age preference in Aphidius ervi (Hymenoptera: Aphidiidae). N Z Plant Prot 59:195-201

Herberich E, Sikorski J, Hothorn T (2010) A robust procedure for comparing multiple means under heteroscedasticity in unbalanced designs. PLoS ONE 5(3):e9788. https://doi. org/10.1371/journal.pone.0009788

Hindayana D, Meyhöfer R, Scholz D, Poehling HM (2001) Intraguild predation among the hoverfly Episyrphus balteatus de Geer (Diptera: Syrphidae) and other aphidophagous predators. Biol Control 20:236-246

Hothorn T, Bretz F, Westfall P (2008) Simultaneous inference in general parametric models. Biom J 50:346-363

Huang XL, Qiao GX (2014) Aphids as models for ecological and evolutionary studies. Insect Sci 21:247-250

Joachim C, Hatano E, David A, Kunert M, Linse C, Weisser WW (2013) Modulation of aphid alarm pheromone emission of pea aphid prey by predators. J Chem Ecol 39:773-782

Khan MR, Khan MR (2002) Prey preference and switching behaviour of Coccinella septempunctata L. (Coleoptera: Coccinellidae). Int J Agric Biol 4:110-112

Letourneau DK, Jedlicka JA, Bothwell SG, Moreno CR (2009) Effects of natural enemy biodiversity on the suppression of arthropod herbivores in terrestrial ecosystems. Annu Rev Ecol Evol Syst 40:573-592

Long EY, Finke DL (2014) Contribution of predator identity to the suppression of herbivores by a diverse predator assemblage. Environ Entomol 43:569-576

Losey JE, Denno RF (1998) Positive predator-predator interactions: enhanced predation rates and synergistic suppression of aphid populations. Ecology 79:2143-2152

Malina R, Praslička J (2008) Effect of temperature on the developmental rate, longevity and parasitism of Aphidius ervi Haliday. Plant Prot Sci 44:19-24

Messing RH, Tremblay MN, Mondor EB, Foottit RG, Pike KS (2007) Invasive aphids attack native Hawaiian plants. Biol Invasions 9:601-607

Milner RJ (1997) Prospects for biopesticides for aphid control. Entomophaga 42:227-239

Nakashima Y, Senoo N (2003) Avoidance of ladybird trails by an aphid parasitoid Aphidius ervi: active period and effects of prior oviposition experience. Entomol Exp Appl 109:163-166

Nakashima Y, Birkett MA, Pye BJ, Powell W (2006) Chemically mediated intraguild predator avoidance by aphid parasitoids: interspecific variability in sensitivity to semiochemical trails of ladybird predators. J Chem Ecol 32:1989-1998

Noppe C, Michaud JP, De Clercq P (2012) Intraguild predation between lady beetles and lacewings: outcomes and consequences vary with focal prey and arena of interaction. Ann Entomol Soc Am 105:562-571

Northfield TD, Snyder GB, Ives AR, Snyder WE (2010) Niche saturation reveals resource partitioning among consumers. Ecol Lett 13:338-348

O'Connor MI, Bruno JF (2009) Predator richness has no effect in a diverse marine food web. J Anim Ecol 78:732-740

Petchey OL (2003) Integrating methods that investigate how complementarity influences ecosystem functioning. Oikos 101:323-330

Petersen LF, Woltz JM (2015) Diel variation in the abundance and composition of the predator assemblages feeding on aphid-infested soybean. BioControl 60:209-219

Riddick EW (2017) Identification of conditions for successful aphid control by ladybirds in greenhouses. Insects 8:38. https://doi.org/10.3390/insects8020038

Rocca M, Messelink G (2017) Combining lacewings and parasitoids for biological control of foxglove aphids in sweet pepper. J Appl Entomol 141:402-410

Schoener TW (1983) Field experiments on interspecific competition. Am Nat 122:240-285

Snyder WE, Ballard SN, Yang S, Clevenger GM, Miller TD, Ahn JJ, Hatten TD, Berryman AA (2004) Complementary biocontrol of aphids by the ladybird beetle Harmonia axyridis and the parasitoid Aphelinus asychis on greenhouse roses. Biol Control 30:229-235

Snyder WE, Snyder GB, Finke DL, Straub CS (2006) Predator biodiversity strengthens herbivore suppression. Ecol Lett 9:789-796

Snyder GB, Finke DL, Snyder WE (2008) Predator biodiversity strengthens aphid suppression across single- and multiplespecies prey communities. Biol Control 44:52-60 
Straub CS, Snyder WE (2006a) Species identity dominates the relationship between predator biodiversity and herbivore suppression. Ecology 87:277-282

Straub CS, Snyder WE (2006b) Experimental approaches to understanding the relationship between predator biodiversity and biological control. In: Brodeur J, Boivin G (eds) Trophic and guild in biological interactions control. Springer, New York, pp 221-239

Straub CS, Finke DL, Snyder WE (2008) Are the conservation of natural enemy biodiversity and biological control compatible goals? Biol Control 45:225-237

Symondson WOC, Sunderland KD, Greenstone MH (2002) Can generalist predators be effective biocontrol agents? Annu Rev Entomol 47:561-594

Vance-Chalcraft HD, Rosenheim JA, Vonesh JR, Osenberg CW, Sih A (2007) The influence of intraguild predation on prey suppression and prey release: a meta-analysis. Ecology 88:2689-2696

Venables WN, Ripley BD (2002) Modern applied statistics with $\mathrm{S}$, 4th edn. Springer, New York

Sanaa N. Alhadidi is a $\mathrm{PhD}$ student investigating the effects of diversity of natural enemies on aphid control.

John N. Griffin is a community ecologist especially interested in the roles of predators in diverse systems and the contribution of biodiversity to ecosystem functioning.

Mike S. Fowler studies the interactions among species and the environmental fluctuations they experience to see how that drives observed population and community dynamics. 